\title{
LIPID-BASED VEHICLE FOR ORAL DRUG DELIVERY
}

\author{
Milan Stuchlík, Stanislav Žák
}

Research, Development and Clinical Department, IVAX-CR a.s., Ostravská 29, 74770 Opava 9, Czech Republic, e-mail: milan_stuchlik@ivax-cr.com

Received: October 18, 2001

Key words: Lipids / Lipophilic drugs / Oral drug delivery systems

With an increasing number of lipophilic drugs under development, homolipids and heterolipids have gained renewed interests as excipients for oral drug delivery systems. Oral administration has many advantages for chronic drug therapy. It is relatively safe, convenient for the patient and allows self administration. This article is not intended to review the broad area of lipid-based vehicle for oral drug delivery comprehensively. The rationale behind choosing lipids materials for pharmaceutical dosage forms and their applications is discussed. It also comments on the methods for monitoring the physicochemical properties of vehicles and formulations and describes a range of pharmacopoeial excipients suitable for these purposes. The excipients selected here are pharmacopoeial in European Pharmacopoeia $4^{\text {th }}$ Ed.,United States Pharmacopoeia $24^{\text {th }}$ Ed./National Formulary $19^{\text {th }}$ Ed. and Japanese Pharmacopoeia $13^{\text {th }}$ Ed. or are drafted in Pharmaeuropa and Pharmacopoeial Forum.

Widening availability of lipidic excipients with specific characteristics offer flexibility of application with respect to improving the bioavailability of poorly water-soluble drugs and manipulating release profiles.

\section{INTRODUCTION}

Lipids are ubiquitously distributed compounds that play fundamental roles in the architecture and functionality of all living cells and therefore are most commonly studied as components of foodstuff and important energy source in the enteral nutrition. Lipids also serve as a source of three families of unsaturated fatty acids ( $\omega-3, \omega-6$ and $\omega-9)$. These three families of fatty acids, represented by its parents member, $\alpha$-linolenic, linoleic and oleic acid have numerous interrelationships which have considerable clinical impact. Ingested food containing lipids can significantly alter postprandial drug absorption and its bioavailability ${ }^{1,2}$.

From the stand point of oral drug delivery, lipids are studied namely as components of various oily liquids and dispersions $3,4,5,6$ that are designed to increase solubility and bioavailability of drugs belonging to the class II. and IV. of the biopharmaceutical drug classification system? ${ }^{7}$.

The reasons for the increasing interest in lipid-based systems are many-fold and include:

- an improved understanding of the manner in which lipids enhance oral bioavailability and reduce plasma profile variability,

- better characterization of lipidic excipients,

- formulation versatility and the choice of different drug delivery systems,

- an improved ability to address the key issues of technology transfer and manufacture scale-up.
Although the physical and chemical formulation-related factors are generally well understood, the impact that physiological factors can have on the performance of lipid-based dosage forms is often less well appreciated. Little attention has been paid to possible alteration in drug metabolism caused by lipidic vehicles used in commercial dosage forms.

Oils administered as a drug vehicle may, for instance, exacerbate changes in hepatic cytochrome P 450 -mediated xenobiotic metabolism that are often reported following ingestion of dosage form . Vegetable and animal oils may have differential effects on specific hepatic CYP isoforms and may add to the variability in metabolism when xenobiotics are administered in lipid-based vehicle $^{8}$.

\section{EXPLANATION OF NOMENCLATURE}

There is no strict definition of the term lipid that is generally accepted. Lipids can be grouped into the following categories based upon their chemical composition.

Table 1. Schematic Lipids Representation

\begin{tabular}{lll} 
Homolipids & Heterolipids & Complex Lipids \\
\hline Cerides (waxes) & Phospholipids & Chylomicrons \\
Glycerides (fats, oils) & $\begin{array}{l}\text { Glycolipids } \\
\text { Sterides }\end{array}$ & Lipoproteines \\
\hline
\end{tabular}




\section{Homolipids}

Homolipids are esters of fatty acids with various alcohols. The principal materials of interest for oral delivery vehicle are long chain and medium chain fatty acids linked to a glycerol molecule, known as triacylglycerols. The long-chain fatty acids ranging from $\mathrm{C} 14$ to 24 appear widely in common fat white the mediumchain fatty acids ranging between $\mathrm{C} 6$ and 12 are typical components of coconut oil or palm kernel oil.

Depending on the carbon chain length, the number and position of double bonds, stereospecificity, triacylglycerols have different physical and chemical properties. Most naturally occuring fatty acids, both of plant and of animal origin are the cis-configuration, although trans-fatty acids are known to occur also in seeds oil from different plant families (Ranunculaceae, Lamiaceae or Asteraceae), natural food products (milk, meat) and some partially modified dietary fats (margarine $)^{9}$.

Structured lipids are triacylglycerols that contain mixtures of either short-chain or medium- chain fatty acids or both, and long-chain fatty acids, preferably esterified on the same glycerol molecule ${ }^{10}$. These were successfully synthesized by lipase-catalyzed interesterification between long-chain fatty acids ethylester and fractionated coconut oils or between caprin/capryl ethylesters and long chain oils ${ }^{11,12}$. Four different molecules of the structured triacylglycerols are schematicaly depicted on figure 1 (the two molecules at the bottom figure exist in two stereoisomers each).

Several well known pharmaceutical excipients are also obtained from marine lipids.

Fish oils are often used for human consumption as food supplements. Appart from pharmacopoeial Omega-3 acid triacylglycerides and Fish oil, rich in omega -3 acids, where origin of the $\omega-3$ polyunsaturated fatty acids is the body oil of the fatty fish species, in liver oil of certain species of shark and elasmobranchii fish, glycerylethers of the 1-O-alkyl-2,3-diacyl-sn-glycerols are the important component ${ }^{13}$. Ether lipids are used as potential anticancer agents mainly in the prevention of leucopenia caused by $\gamma$-radiation ${ }^{14}$.

Diacylglycerols are found in vegetable oils in low amounts (between 1 and $10 \%$ ). They are formed as intermediate products in biosyntesis of triacylglycerols, as well as by acidic and enzymatic hydrolysis during oil extraction, refining and storage. Simultaneously, isomerisation processes produce changes in the composition of the diacylglycerols. Knowledge of the quantity and composition of diacylglycerols is, therefore, of great interest for the evaluation of the quality of the oil and of the treatments to which the oil is subjected ${ }^{15}$.

The non-glyceride fraction of vegetable and animal oils (unsaponifiable matter) consists of a mixture of minor lipids component such as sterols, squalene, triterpenic alcohols and vitamins (tocopherols, calciferols, retinol).Each of these components of the unsaponifiable matter has specific functional properties of great impor- tance for topical formulations but practically nothing is known about its impact in oral formulations. Only patients wit sitosterolemia have a very high absorption rate of phytosterols and show serious side effects leading to to premature atherosclerosis.

\section{Heterolipids}

The emphasis of this chapter will be on the phospholipids only. Two main classes of phospholipids occur naturally in qualities sufficient for pharmaceutical applications. These are the phosphoglycerides and phosphosphingolipids. Some phosphosphingolipids such as ceramide are used mainly in topical dosage forms.

Phospholipids can be obtained from all types of biomass because they are essential structural components in all kinds of membranes of living organisms. However, commercial sources are largely limited to vegetable oil seeds such as soyabeans, for pharmaceutical and some dietetic application, the egg yolk and milk have gained also importance as sources of phospholipids ${ }^{16}$.

The most commonly used term for phosphoglycerides is "lecithin". Our understanding of the trivial name lecithin is still unclear, even today. Contrary to the understanding of the term lecithin as 1,2-diacyl-snglycero-3-phosphocholine (= phosphatidylcholine), the word is also used in USP/NF monograph to describe a complex mixture of phospholipids, triacylglycerols, glycolipids, carbohydrates, sterol, diacylglycerols and free fatty acids. In the draft of pharmacopoeial monograph Soya Lecithin ${ }^{17}$ is also defined as this complex mixture.

Processing of the complex lecithin mixture usually starts with deoiling with acetone. The content of phosphatides determined as matter insoluble in acetone must be in pharmacopoeial quality not less than $50 \%$. Further extraction of the standartized native soybeen lecithin by ethanol and chromatographic separation using aluminium oxide enables the manufacture of phospholipid-enriched lecithin fractions with completely new functionalities.

Table 2. Composition of the acetone-deoiled lecithins

\begin{tabular}{llc} 
Composition & $\begin{array}{l}\text { Soybean } \\
\text { lecithin }\end{array}$ & $\begin{array}{l}\text { Egg } \\
\text { lecithin }\end{array}$ \\
\hline Phosphatidylcholine & $21-22 \%$ & $73-74 \%$ \\
Phosphatidylethanolamine & $14-23 \%$ & $17-19 \%$ \\
Phosphatidylserine & $<2 \%$ & - \\
Phosphatidylinositol & $12-20 \%$ & $0.4-1 \%$ \\
Phosphatidic acid & $5-6 \%$ & - \\
Phosphatidyl- & $2.3 \%$ & $0.6 \%$ \\
/diphosphatidylglycerol & & $2.5-3 \%$ \\
Sphingomyelin & - & $<3 \%$ \\
Lysophospholipids* & $<3 \%$ & \\
\hline
\end{tabular}

* Small amounts of the monoacylderivatives of all diester species are found in all natural phospholipids. 
The phospholipids in the lecithin complex have different chemical structures. Various processing methods have been developed, by which phospholipid fractions with differently enriched phospholipids are acquired. The removal of most of the glycerides and fatty acids of lecithin produces "deoiled" lecithin with a 90 percent or more phospholipid content. The phospholipids contain two fatty acid chains (hydrophobic tail) usually with even carbon number. The fatty acids may be saturated or unsaturated and their configuration is nearly always cis. Phospholipids are, therefore, non-homogenous materials with mainly saturated acyl chains at the $s n-1$ position and unsaturated acyl chains at the $s n-2$ position. Fatty acid distribution in individual phospholipids from one source differs and may become a quality criterion for their application in pharmaceutical dosage forms.

Table 3. Distribution of the fatty acids ( $\%$ by weight) in the phospholids of soybean lecithin

\begin{tabular}{lrrrr} 
Fatty acids & PC & \multicolumn{1}{c}{ PE } & \multicolumn{1}{c}{ PI } & \multicolumn{1}{c}{ PA } \\
\hline & & & & \\
Stearic acid & 20.5 & 31.6 & 47.7 & 34.0 \\
Palmitic acid & 5.5 & 3.2 & 8.2 & 8.1 \\
Oleic acid & 10.5 & 8.7 & 4.9 & 11.9 \\
Linoleic acid & 58.8 & 53.2 & 36.2 & 44.7 \\
Linolenic acid & 4.6 & 3.2 & 2.8 & 1.3 \\
\hline
\end{tabular}

Recently, the distribution of fatty acids in the phospholipids according to the differences in carbon number and degree of unsaturation by micellar electrokinetic chromatography was described ${ }^{18}$.

Enzyme-modified lecithins are prepared mainly from various types of crude or deoiled material, using either purified phospholipase $A_{2}$ or pancreatin. Use of this enzyme allows the removal/replacement of the acyl chain at position $s n-2$ either via hydrolysis and subsequent chemical reesterification or through direct interesterification with an acyl donor. The resulting products contain lysophospholipids and fatty acids as well as other components of lecithin. Inactivated phospholipase and calcium chloride are also present in such enzyme-modified lecithins $(\mathrm{Ca}$ ions are required for the enzyme activation). In accordance with FDA decision the use of enzyme-modified lecithin as an emulsifier in foods is generally recognized as safe.

The enzyme that has the specific capacity to catalyse the hydrolysis of the acyl chain at the $s n-1$ position is not commercially available.

Modification of the polar heads of natural or synthetic phospholipids by phospholipase D has been applied in the industrial preparation of less-abundant phospholipids and for preparation of modified ether phospholipids. Phospholipase D hydrolyses L- $\alpha$-phosphatidylcholine to phosphatidic acid and choline. In the presence of an alcohol,transphosphatidylation can occur with different degrees of selectivity depending on the nature of alcohol and its concentration.

\section{Complex lipids}

Lipoproteins are spherical lipid-protein complexes that are responsible for the transport of cholesterol and other lipids within the body. Structurally, lipoprotein consists of an apolar core composed of cholesterol esters or triacylglycerols, surrounded by monolayer of phospholipid in which cholesterol and one or more specific apoproteins are embedded.

Natural lipoproteins are defined into four major classes called chylomicron, very low density lipoprotein (VLDL), low density lipoprotein (LDL) and high density lipoprotein (HDL). The different lipoproteins vary in size and density and show differences in lipid and apoprotein composition. The physicochemical properties of these lipoproteins are mentioned in the following table.

Table 4. Physicochemical parameters for lipoproteins*

\begin{tabular}{|c|c|c|c|c|}
\hline & Chylomicron & VLDL & LDL & HDL \\
\hline Density $(\mathrm{g} / \mathrm{ml})$ & $<0.950$ & $<1.006$ & $1.019-1.063$ & $1.003-1.210$ \\
\hline Size (nm) & $80-100$ & $30-90$ & $20-25$ & $8-12$ \\
\hline $\begin{array}{l}\text { Phospholipids } \\
(\%)\end{array}$ & $3-6$ & $15-20$ & $18-24$ & $26-32$ \\
\hline Cholesterol (\%) & $1-3$ & $4-8$ & $6-8$ & $3-5$ \\
\hline $\begin{array}{l}\text { Triacylglycerols } \\
(\%)\end{array}$ & $80-95$ & $45-65$ & $4-8$ & $2-7$ \\
\hline Proteins $(\%)$ & $1-2$ & $6-10$ & $18-22$ & $45-55$ \\
\hline
\end{tabular}

* taken and processed from ${ }^{19}$

\section{FORMULATION APPROCHES}

The bioavailability of lipophilic drugs when administered orally as solid dosage forms is notoriously low. There are usually several factors responsible for this, but a particularly widespread problem is poor absorption due to slow and/or incomplete drug dissolution in the lumen of the gastro-intestinal tract. In this case, improved bioavailability can be achieved by the use of delivery systems which can enhance the rate and/or the extent of drug solubilizing into aqueous intestinal fluids.

For a lipophilic drug compound, the principle objective is to achieve a formulation where the drug is dissolved in the liquid vehicle. Once present in the gastro-intestinal tract, the liquid vehicle is diluted by the surrounding physiological fluid. During this dilution stage, the lipophilic drug may remain in solution, may form a liquid dispersion or it may precipitate as a fine suspension.

By selecting the optimum liquid vehicle composition, it is possible to minimise or eliminate precipitation of the drug.

There are several different categories of vehicles which can be selected in order to prepare a lipidic carrier. Such formulations can be used as oral liquids or can be encapsulated into various types of capsules. The 
finished product is then administered to the patient as a solid dosage form.

\section{Lipophilic liquid}

Some lipophilic drugs such as steroids have appreciable solubility in triacylglycerols alone. It is therefore comparatively straightforward to administer the drug in an oily liquid (e.g. encapsulated) and thereby achieve satisfactory absorption. One disadvantage of this formulation approach, however, is that oil alone rarely provides the solubilizing power to dissolve the required dose in a reasonable quantity of oil. This limits the option of using a simple drug / oil formulation system.

\section{Self-emulsifying oil systems}

The ability of an oil to accommodate a hydrophobic drug in solution can be improved by the addition of surfactants. The surfactants also perform the function of dispersing the liquid vehicle on dilution in gastrointestinal fluid. Hence, the drug is present in fine droplets of the oil / surfactants mixture which spread readily in the gastro-intestinal tract.

\section{Micro-emulsifying systems}

Micro emulsions consist of a lipophilic or oily phase in combination with one or more surfactants such that the resulting liquid is almost clear. The lipophilic drug is therefore dissolved in a formulation containing hydrophilic surfactant and oil which produces a micro-emulsion preconcentrate. Micro-emulsion particles are essentially surfactant micelles swollen with solubilized oil and drug.

Solid lipid nanoparticles- To overcome the disadvantages associated with the liquid state of the oil droplets, the liquid lipid was replaced by a solid lipid leading to the formation of solid lipid nanoparticles. In contrast to emulsions, the particles consist of a solid core made from solid lipids. They are characterized by a mean diameter between approx. 100 to $1000 \mathrm{~nm}$. There are two basic production techniques for solid lipid nanoparticles, homogenization of melted lipids at elevated temperature (Figure 2) and homogenization of a suspension of solid lipids at room temperature or below (Figure 3).

\section{Liposomes}

In liposomes, amphiphilic phospholipid molecules are arranged in a closed spherical bilayer. The lipophilic fatty acids component of the molecules are facing each other. Liposoluble drugs can be embedded in the "fatty" regions, while hydrophilic substances are held in the aqueous internal spaces of these globular vesicles. Their ability to convey, protect and penetrate can be exploited also in oral drug delivery.

\section{Modified lipoproteins}

Lipoproteins can be directed to nonlipoproteins receptors, specifically to various types of liver cells, by providing the apoprotein with recognition marker. This can be achieved by semisynthetic modification of the LDL or HDL.

Endothelial liver cells have a receptor called "the scavenger receptor" which specifically recognises negatively charged ligands ${ }^{20}$. The parenchymatous liver cells and Kupffer cells have galactose specific receptors ${ }^{21}$. Incubation of lipoproteins (LDL or HDL) with lactose and sodium cyanoborhydrate or incubation of LDL with acetic anhydride leads to modified lipoproteins which can be effectively used as drug carriers.

Another similar system "Supramolecular Biovectors" synthetically prepared, was constructed so as to mimic $\mathrm{LDL}^{22}$. The novel systems are composed of an external phospholipidic shell, on to which appoproteins are anchored. The lipoproteins lipidic core is replaced by cross linked natural polysacharide which has been acylated on its surface fatty acids to give it a peripheral hydrophobic nature. These LDL mimicking particles (size range from $10 \mathrm{~nm}$ to a few microns) allow the entrapment of various drugs, not only lipophilic.

\section{POTENTIAL CARRIERS}

The following tables list the pharmacopoeial vegetable oils and animal fats and oils of natural origin, used most commonly for manufacturing of lipidic oral formulations.

Table 5. Pharmacopoeial Vegetable Oils

\begin{tabular}{llll} 
Name / Source & PhEur & $\mathrm{USP} / \mathrm{NF}$ & $\mathrm{J} \mathrm{Ph}$ \\
\hline & & & \\
Almond oil / Prunus dulcis & $+(\mathrm{R}, \mathrm{V})$ & - & - \\
Arachis oil (Peanut oil) & $+(\mathrm{R}, \mathrm{H})$ & - & + \\
/ Arachis hypogea & - & - & + \\
Camellia oil / Camellia japonica & $+(\mathrm{V}, \mathrm{H})$ & + & + \\
Castor oil / Ricinus communis & $+(\mathrm{R})$ & - & + \\
Coconut oil / Cocos nucifera & $+(\mathrm{H})$ & + & - \\
Cottonseed oil / Gossypium hirsutum & + & + \\
Maize oil (Corn oil) Zeya mais & $+(\mathrm{R})$ & + & + \\
Olive oil Olea europaea & $+(\mathrm{R}, \mathrm{V})$ & + & + \\
Rapeseed oil / Brassica napus, & & & \\
B. campestris & $+(\mathrm{R})$ & - & + \\
Safflower oil / Carthamus tinctorius & - & + & - \\
Sesame oil / Sesamum indicum & $+(\mathrm{R})$ & + & + \\
Soyabeen oil /Glycine soja, G. max & $+(\mathrm{R}, \mathrm{H})$ & - & + \\
Sunflower oil /Helianthus annuus & $+(\mathrm{R})$ & - & - \\
Triglycerides, media chain & & & \\
/ Cocos nucifera, Elaeis guineensis & + & + & - \\
Wheat germ oil / Triticum aestivi & $+(\mathrm{R}, \mathrm{V})$ & - & - \\
\hline
\end{tabular}


Table 6. Pharmacopoeial Animal Fats and Oils

Name / Source PhEur USP/NF JPh

Beef tallow (Sevum bovinum)

/ Bos taurus var. Domesticus

Hard fat (Adeps solidus)

/ Semisyntehetic from natural FA

Lard (Adeps suillus) / Sus scrofa

Cod-liver oil (Iecoris aselli oleum)

/ Gadus morhua; Gadidae

Fish oil (Piscis maritimi oleum)

/ Engualidae, Carangidae,

Clupeidae, Osmeridae, Scrombroidae,

Ammodytidae

Omega-3-acid triglycerides

(Omega-3 acidorum trigycerida) /

Engaulidae, Carangidae, Clupeidae,

Osmeridae, Salmonidae,

Scrombroidae

Shark liver oil

/ Somniosus microcephalus,

Lamna nasus

$\begin{array}{llll}- & - & + \\ + & - & - \\ + & - & + \\ + \text { type A, B - } & +\end{array}$

Notes to Tables 5 and 6

R - Refined oil; V - Virgin oil; H - Hydrogenated oi. (+) Draft of pharmacopoeial monograph published in Pharmacopoeial Forum

A number of vegetable oils have been in pharmaceutical use for a long period in the entire world (e.g. maize oil, olive oil, sesame oil) while the others are typical only for some territories (e.g. camellia oil for Japan, wheat germ oil for Europe, safflower oil for United States). The oily excipients could be selected according to the fatty acids composition. Typical fatty acids composition of the pharmacopoeial vegetable oils, fish oils and semisynthetic oils are demonstrated in tables 7, 8 and 9.

Vegetable oils are obtained from the seed, the fruit or the pit/stone/kernel of various plants. They may be obtained by expression and/or extraction, than possibly refined or hydrogenated. When the plants have high oil content, the oil is generally obtained by expression under heating followed by extraction. When the plant has a low oil content, the oil is generally obtained by direct extraction. The oil obtained by cold expression without heating is named virgin oil.

After obtaining a crude oil, alkali refining or physical refining is usually performed.Alkali refining consists in the following steps: degumming, neutralisation, washing and drying ; physical refining consists in steam distillation of the oil under high vacuum at a temperature $>235^{\circ} \mathrm{C}$. Technique of the physical refining cannot be used for heat sensitive oils (cottonseed oil) which darken. In high purity applications the oil may be purified by passing the oil through a column containing an activated earth (superrefining oils). High polarity molecules such as oxidised materials, acids and alcohols are preferentially removed.

The objective of refining is to remove impurities and contaminants of the oil. The contents of the following substances are reduced:

- free fatty acids which may cause deterioration of the oil by oxidation,

- partial glycerides which may cause foaming and bitter taste,

- phosphatides and phosphorous compounds which have emulsifying properties,

may cause claudy aspect or deposit and bad organoleptic sdtability,

- colouring matters such as chlorophyll, carotenoids or gossypol,

- free hydrocarbons and glycolipids which may form colloidal solutions with water,

Table 7. Typical fatty Acid Composition of the Pharmacopocial Vegetable Oils

\begin{tabular}{|c|c|c|c|c|c|c|c|c|c|c|c|c|}
\hline \multicolumn{2}{|c|}{ Fatty acid } & \multirow{2}{*}{$\begin{array}{c}\text { Almond oil } \\
\text { Virgin, } \\
\text { Refined }\end{array}$} & \multirow{2}{*}{$\begin{array}{l}\text { Arachis oil } \\
\text { Refined }\end{array}$} & \multirow{2}{*}{$\begin{array}{l}\text { Castor oil } \\
\text { Virgin }\end{array}$} & \multirow{2}{*}{$\begin{array}{c}\begin{array}{c}\text { Coconut oil } \\
\text { Refined }\end{array} \\
<1.5\end{array}$} & \multirow{2}{*}{$\begin{array}{l}\text { Maize oil } \\
\text { Refined }\end{array}$} & \multirow{2}{*}{$\begin{array}{l}\text { Olive oil Virgin, } \\
\text { Refined }\end{array}$} & \multirow{2}{*}{$\begin{array}{l}\text { Rapeseed oil } \\
\text { Refined }\end{array}$} & \multirow{2}{*}{$\begin{array}{l}\text { Sesame oil } \\
\text { Refined }\end{array}$} & \multirow{2}{*}{$\begin{array}{l}\text { Soya bean oil } \\
\text { Refined }\end{array}$} & \multirow{2}{*}{$\begin{array}{l}\text { Sunflower oil } \\
\text { Refined }\end{array}$} & \multirow{2}{*}{$\begin{array}{l}\text { Wheat germ oil } \\
\text { Virgin, Refined }\end{array}$} \\
\hline Caproil & 6:0 & & & & & & & & & & & \\
\hline Caprylic & $8: 0$ & & & & $5-11$ & & & & & & & \\
\hline Capric & $10: 0$ & & & & $4-9$ & & & & & & & \\
\hline Lauric & $12: 0$ & & & & $40-50$ & & & & & $<0.1$ & & \\
\hline Myristic & $14: 0$ & $<1$ & $<0.4$ & & $15-20$ & $<0.6$ & $<0.1$ & & $<0.1$ & $<0.2$ & & \\
\hline Palmitic & $16: 0$ & $4-9$ & $7-16$ & $<2$ & $7-12$ & $8.6-16.5$ & $7.5-20$ & $2.5-6$ & $7.9-10.2$ & $9-13$ & $4-9$ & 14-19 \\
\hline Palmitooleic & $16: 1$ & $<0.2$ & & & & & $<3.6$ & & $<0.2$ & $<0.3$ & & \\
\hline Margaric & $17: 0$ & $<0.2$ & & & & & & & & & & \\
\hline Stearic & $18: 0$ & $<3$ & $1.3-6.5$ & $<2.5$ & $1.5-5$ & $<3.3$ & $0.5-5$ & $<3$ & $4.8-61$ & $3-5$ & $1-7$ & $<2$ \\
\hline 9,10dihydros & $\begin{array}{l}\text { earic } \\
18: 0 \\
\end{array}$ & & & $0.3-0.7$ & & & & & & & & \\
\hline Ricinooleic & $18: 1$ & & & $85-92$ & & & & & & & & \\
\hline Oleic & $18: 1$ & $62-86$ & $3.5-7.2$ & $2.5-6$ & $4-10$ & $20-42.3$ & $56-85$ & $50-67$ & $35.9-42.3$ & $17-30$ & $14-40$ & $12-23$ \\
\hline Linolenic & $18: 2$ & $20-31$ & $13-43$ & $2.5-7$ & $1-3$ & $39.4-63.6$ & $3.5-20$ & $16-30$ & $41.5-47.9$ & $48-58$ & $48-74$ & $52-59$ \\
\hline Linolenic $\alpha$ & $18: 3$ & $<0.4$ & $<0.6$ & $<1$ & $<0.2$ & $0.3-1.3$ & $<1.2$ & $6-14$ & $<0.4$ & $5-18$ & & $3-10$ \\
\hline Arachidic & $20: 0$ & $<0.2$ & $1-3$ & & $<0.2$ & $<0.2$ & $<0.7$ & & $<0.6$ & $<1$ & & \\
\hline Eicosenoic & $20: 1$ & $<3$ & $0.5-2.1$ & $<1$ & $<0.2$ & $<0.5$ & $<0.4$ & $<5$ & $<0.3$ & $<1$ & & $<2$ \\
\hline Behenic & $22: 0$ & $<2$ & $1-5$ & & & $<1.5$ & $<0.3$ & & $<0.3$ & $<1$ & & \\
\hline Erucic & $22: 1$ & $<0.1$ & $<0.5$ & & & & & $<2$ & & & & \\
\hline Lignoceric & $24: 0$ & & $0.5-3$ & & & & $<0.2$ & & $<0.3$ & & & \\
\hline Nervonic & $24: 1$ & & & & & & & & & & & \\
\hline Any other & & & & $<1$ & & & & & & & & \\
\hline
\end{tabular}

Remark: The table is compiled European Pharmacopoeia and draft monographs published in Pharmaeuropa

$* \quad$ The fatty acid fraction of the Sesame oil has the stated composition, but in official monographs only triglyceride composition is determined and depictured in Figure 4. OLL 13 to $30 \%$, OOL 14 to $25 \%$, LLL 7 to $19 \%$, POL 8 to $16 \%$ OOO 5 to $9 \%$, SOL 2 to $8 \%$, POO 2 to $8 \%$ 
Table 8. Typical fatty Acid Composition of the Pharmacopoeial Fish Oils

\begin{tabular}{|c|c|c|c|c|}
\hline \multicolumn{2}{|l|}{\begin{tabular}{|l|} 
Fatty acid \\
\end{tabular}} & \multirow{2}{*}{\begin{tabular}{|c|}
$\begin{array}{l}\text { Cod liver oils, } \\
\text { type A, B }\end{array}$ \\
$2-6 \%$ \\
\end{tabular}} & \multirow[t]{2}{*}{$\begin{array}{l}\text { Fish oil, } \\
\text { rich in } \omega \text {-acids }\end{array}$} & \multirow[t]{2}{*}{$\omega-3$ acid triglycerides } \\
\hline \begin{tabular}{|l|} 
Myristic \\
\end{tabular} & 14:0 & & & \\
\hline Palmitic & 16:0 & $7-14 \%$ & & \\
\hline \begin{tabular}{|l} 
Palmitooleic \\
\end{tabular} & $16: 1, n-7$ & $4.5-11.5 \%$ & & \\
\hline Stearic & 18:0 & $1-4 \%$ & & \\
\hline Vacenic & $18: 1, \mathrm{n}-7$ & $2-7 \%$ & & \\
\hline Oleic & $18: 1, \mathrm{n}-9$ & $12-21 \%$ & & \\
\hline Linoleic & $18: 2, \mathrm{n}-6$ & $0.5-3 \%$ & & \\
\hline Linolenic & $18: 3, n-3$ & $<0.2 \%$ & & + \\
\hline Moroctic & $18: 4, \mathrm{n}-3$ & $0.5-4 \%$ & & + \\
\hline Gadoleic & $20: 1, \mathrm{n}-11$ & $1-5.5 \%$ & & \\
\hline Gondoic & $20: 1, n-9$ & $5-17 \%$ & & \\
\hline ETA* & $20: 4, n-3$ & & & + \\
\hline \begin{tabular}{|l|} 
Timnodonic \\
\end{tabular} & $20: 5, n-3$ & $7-16 \%$ & $>13 \%$ & + \\
\hline HPA* & $21: 5, n-3$ & & & + \\
\hline Cetoleic & $22: 1, \mathrm{n}-11$ & $5-12 \%$ & & \\
\hline Erucic & $22: 1, n-9$ & $>1.5 \%$ & & + \\
\hline Clupanodonic & $22: 5, n-3$ & & & + \\
\hline Cervonic & $22: 6, n-3$ & $6-18 \%$ & & + \\
\hline Total $\omega$-3 Acid & & $15.5-38 \%$ & $>23 \%$ & $>60 \%$ \\
\hline $\mathrm{EPA}+\mathrm{DHA}$ & & & & $>45 \%$ \\
\hline
\end{tabular}

* ETA - eicosatetraenoic acid; HPA - heneicosapentaenoic acid

** Timnodonic acid - EPA (eicosapentaenoicic acid)

Cervonic acid - DHA (docosahexaenoic acid)

Table 9. Typical Fatty Acid Composition of the Pharmacopoeial Hydrogenated Vegetable Oils and Semisynthetic Triglyceride

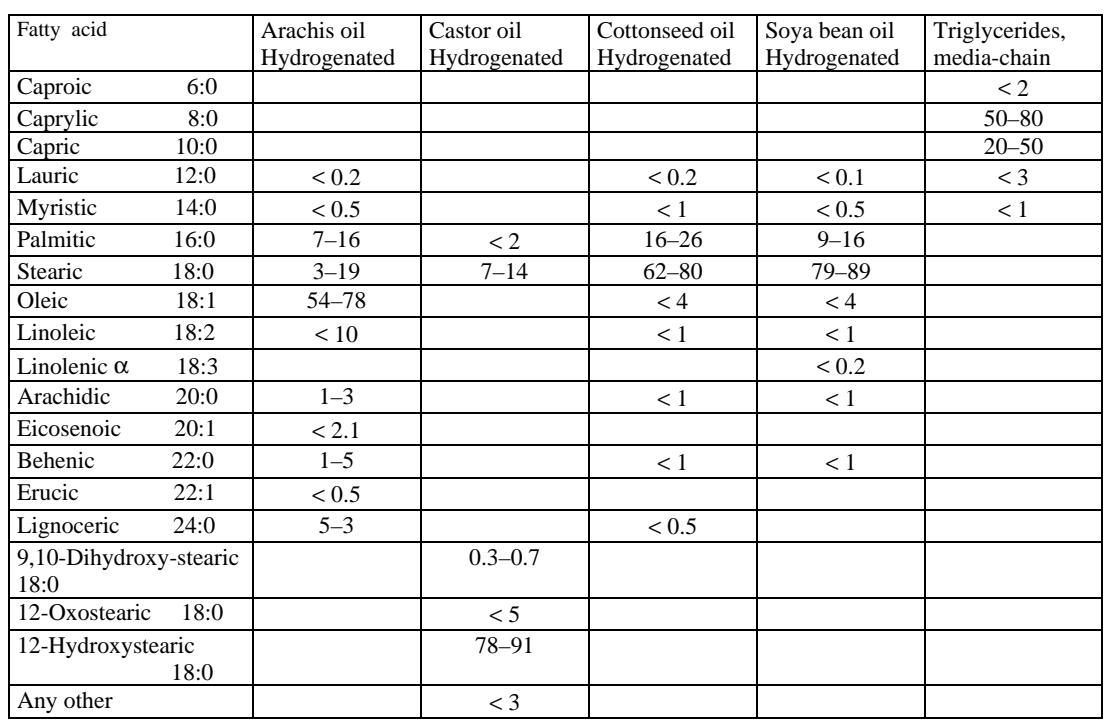

Remark: According USP-NF hydrogenated vegetable oils are distinguished on theType I and Type II. The melting range, iodine value and saponification value differ, depending Type, as set forth in the accompanying table.

$\begin{array}{lll} & \text { Type I } & \text { Type II } \\ \text { Melting range } & 45^{\circ} \text { to } 85^{\circ} & 20^{\circ} \text { to } 50^{\circ} \\ \text { Iodine value } & 0 \text { to } 5 & 55 \text { to } 80 \\ \text { Saponification value } & 175 \text { to } 200 & 175 \text { to } 2\end{array}$


- heavy metals which are strong oxidation catalysts $(\mathrm{Fe}, \mathrm{Cu}, \mathrm{Pb}, \mathrm{Sn})$ and residual hydrogenation catalysator $(\mathrm{Pt}, \mathrm{Pd})$,

- proteins having possible allergic reactions or mycotoxins (as aflatoxin of arachis oil),

- pesticides, oxidation products, paraffins, waxes and resinous materials, unsaponifiable matters (e.g. lignins, sterols, tocopherols).

Unsaponifiable matter of pharmacopoeial vegetable oils do not usually exceed $5 \%$. However, there are some oils which contain higher amount of unsaponifiable matter due to phytosterols (sheanut oil) or squalene (amaranth oil). Sterol composition of the pharmacopoeial vegetable oils and limits of unsaponifiable matter are listed in table 10. In nature, plant sterols occur primarily in the unhydrogenated free form. Their intestinal absorption is less than $5 \%$ and plasma levels are generally less than $1 \%$ of cholesterol levels.

Medium chain triacyl glycerols may be useful as drug carriers, as they are thought to have no pharmacological action ${ }^{23}$. They are the subject of intraluminal hydrolysis and are mainly absorbed as free fatty acids. Intraluminal digestion, uptake by the mucosal cells, and transport to the systemic circulation of medium chain triacylglycerols and long chain triacyl glycerols are distinct $^{24,25}$. Their potential for promoting bioavailability has been known for many years, but e.g. ciclosporin is absorbed from medium chain triacyl glycerols significantly lower than with long chain triacyl glycerols ${ }^{26}$.

Partial glycerides of saturated and unsaturated fatty acids are also used as pharmacopoeial excipients. Partial glycerides are defined as mixtures of monoesters,1,3diesters ,1,2-diesters and triesters of glycerol which may be obtained either by glycerolysis of vegetable oils and hydrogenated oils or by esterification of glycerol with corresponding fatty acids. Monoacylglycerols are the simplest and the most commonly used group of functional lipids,but practically exist only as an equilibrium mixture of about $90 \%$ of the 1 -isomer and $10 \%$ of the 2-isomer ${ }^{27}$. The pure 2-isomers, which today can be prepared to a reasonable purity enzymatically, exhibit different physical properties and are not commonly used because of price reason.

Unsaturated monoacylglycerols, depend on the water content form various lyotropic liquid crystalline phases, which can be used as sustained release carriers of amphiphilic drug molecules ${ }^{28}$. Mono and diacylglycerols of medium chain fatty acids have a multifunctional properties. The main use is as absorption enhancer. Due to its tensoactive properties it can be used as emulsifier for microemulsions. Their capability of retarding the growth of sensible microorganisms is well known.

Each pharmacopoeial partial glyceride of fatty acid is characterized by its nominal saponification value, its nominal fatty acid content and its nominal monoglyceride, diglyceride and triglyceride content. It contains not more than $7 \%$ of free glycerol. When partial glycerides are produced from tissues of mammalian animals or other materials obtained from warm-blooded animals, the animals must fulfil the requirements for the health of animals suitable for human consumption to the satisfaction of the competent authority. Furthemore the tissues shall not include any specified risk materials as defined by any relevant legislation.Table 11 lists the pharmacopoeial partial acylglycerols.

Closely related to the partial acylglycerols are partial acylglycoles based on ethylenglycole, diethylenglycole and proplylenglycole. Acylglycoles may form a substantial part in lipids of some marine animals (e.g. star fish) or microbial lipids ${ }^{29}$. The Pharmacopoeia Europea contains individual monographs of the ethyleneglycol monostearate, ethyleneglycol monopalmitostearate, diethyleneglycol monopalmitostearate, propyleneglycol monostearate and propyleneglycol monopalmitostearate.

The components of the pharmacopoeial soybean lecithin differs according to the plant variety, climate, degree of ripeness and processing conditions. Structural diversity of the phospholipid molecules is reflected in the differing physycal and chemical properties of the phospholipids.

Phosphatidylcholine(PC) is a good oil/water emulsifier and the most characteristic excipient of the liposomes. At a physiological $\mathrm{pH}$, phosphatidylcholine has a zwitterionic structure. Salt formation with divalent cations such $\mathrm{Ca}^{2+}$ is therefore only slight. Relative size of the hydrophilic head group,which is larger than that of phosphatidylethanolamine and phosphatidic acid, gives the fatty acids "tails" greater freedom of movement. This enables a lower transition temperature from liquid to crystalline structure than is the case with other phospholipids. In practice it is possible to influence viscosity reduction and flow behaviour in fats to a greater extent with the phosphatidylcholine-enriched fractions than with native soybean lecithin.

Phosphatidylethanolamine (PE) is a good co-emulsifier for phosphatidylcholine.This property is demonstrated by the superior efficacy of the defined phosphatidylcholine/phosphatidylethanolamine mixtures as compared to undefined mixtures in both water/oil or in oil/water emulsions. Like phosphatidylcholine it has a zwitterionic structure and is therefore insensitive to divalent ions when dispersed in water. Compared to phosphatidylcholine,phosphatidylethanolamine has a smaller head group. This means that if phosphatidylethanolamine is incorporated in a bilayer membrane the fatty acids have limited freedom of movement. This results in restricted deformability of the membrane and 20 to $25{ }^{\circ} \mathrm{C}$ higher transition temperature from the crystalline to the liquid state. Unlike phosphatidylcholine, phosphatidylethanolamine - being a monosubstance - does not form a bilayer membrane in water and therefore does not form liposomes either. Nevertheless, biological membranes always have some phosphatidylethanolamine content. It functions to stabilize the membranes; stability is achieved by closer packing of the molecules. 
Table 10. Unsaponifiable Matter and Typical Sterol Composition of the Pharmacopocial Vegetable Oils

\begin{tabular}{|c|c|c|c|c|c|c|c|c|c|c|c|}
\hline Fatty acid & \begin{tabular}{|c|} 
Almond oil \\
Virgin, \\
Refined \\
\end{tabular} & $\begin{array}{c}\text { Arachis oil } \\
\text { Refined }\end{array}$ & $\begin{array}{l}\text { Castor oil } \\
\text { Virgin }\end{array}$ & $\begin{array}{l}\text { Coconut oil } \\
\text { Refined }\end{array}$ & $\begin{array}{c}\text { Maize oil } \\
\text { Refined }\end{array}$ & $\begin{array}{l}\text { Olive oil Virgin, } \\
\text { Refined }\end{array}$ & $\begin{array}{l}\text { Rapeseed oil } \\
\text { Refined }\end{array}$ & $\begin{array}{l}\text { Sesame oil } \\
\text { Refined }\end{array}$ & $\begin{array}{l}\text { Soya bean oil } \\
\text { Refined }\end{array}$ & $\begin{array}{l}\text { Sunflower oil } \\
\text { Refined }\end{array}$ & $\begin{array}{l}\text { Wheat germ oil } \\
\text { Virgin, Refined }\end{array}$ \\
\hline $\begin{array}{l}\text { Unsaponifiable } \\
\text { Matter }\end{array}$ & $<0.7 \%$ & $<1.0 \%$ & $<0.8 \%$ & $<\%$ & $<2.8 \%$ & $<1.5 \%$ & $<1.5 \%$ & $<1.8 \%$ & $<1.5 \%$ & $<1.5 \%$ & $<5.0 \%$ \\
\hline $\begin{array}{l}\text { Composition of the } \\
\text { Sterol Fraction }\end{array}$ & $\%$ & $\%$ & $\%$ & $\%$ & $\%$ & $\%$ & $\%$ & $\%$ & $\%$ & $\%$ & $\%$ \\
\hline 45-Avenasterol & $<10 ;<5$ & & & & & + & $<3$ & & & $2-6$ & $4-8$ \\
\hline$\Delta 7$-Avenasterol & $<3 ;<3$ & & & & & & & & & & $<3$ \\
\hline Brassicasterol & $<0,3 ;<0.3$ & & & & $<0.3$ & & $7-13$ & & $<0.3$ & & $<0.3$ \\
\hline Campesterol & $<4 ;<5$ & & & & & $<4$ & $20-30$ & & & $5-10$ & $20-25$ \\
\hline Cholesterol & $<0,7 ;<0.7$ & & & & & $<0.5$ & & & & & \\
\hline Clerosterol & & & & & & + & & & & & \\
\hline Sitostanol & & & & & & + & & & & & \\
\hline$\beta$-Sitosterol & $73-87$ & & & & & + & $55-65$ & & & $55-65$ & $60-72$ \\
\hline $\begin{array}{l}\Delta 5,23- \\
\text { Stigmastadienol }\end{array}$ & & & & & & + & & & & & \\
\hline $\begin{array}{l}\Delta 5,24- \\
\text { Stigmastadienol }\end{array}$ & & & & & & + & & & & & \\
\hline Stigmasterol & $<3 ;<4$ & & & & & & & & & $5-10$ & \\
\hline$\Delta 7$-Stigmasterol & $<3 ;<3$ & & & & & $<0.5$ & $<7$ & & & $12-18$ & $1-4.5$ \\
\hline
\end{tabular}

Remarks: The table is compiled according European Pharmacopoeia and draft monographs published in Pharmacopoeia 1996, Vol. 8, No. 378-380. Limits of the individual sterols drafted for rapeseed oil, sunflower oil and wheat germ oil were not adopted in to final monographs.

+ Sum of contents of these sterols: not less than $93.0 \%$

Table 11. List of Pharmacopoeial Partial Acylglycerols

\begin{tabular}{|c|c|c|c|c|c|}
\hline & \multicolumn{5}{|c|}{ Content of acylglycerols } \\
\hline & Mono- & Di- & Tri- & Oligomers & Free glycerol \\
\hline Glycerol dibehenate & $13-21 \%(12-18 \%)$ & $40-60 \%$ & $21-35 \%$ & --- & $<1 \%$ \\
\hline Glycerol distearate, type I-III * & $8-22 \%$ & $40-60 \%$ & $25-35 \%$ & & $<1 \%$ \\
\hline Glycerol monolinoleate & $32-52 \%$ & $40-55 \%$ & $5-20 \%$ & & $<6 \%$ \\
\hline $\begin{array}{ll} & 40 \\
\text { Glycerol monooleate, type } & 60 \\
& 90\end{array}$ & $\begin{array}{l}32-52 \% \\
55-65 \% \\
90-101 \%\end{array}$ & $\begin{array}{c}30-50 \% \\
15-35 \% \\
<10 \%\end{array}$ & $\begin{array}{l}5-20 \% \\
2-10 \% \\
<2 \%\end{array}$ & & $\begin{array}{l}<6 \% \\
<6 \% \\
<6 \%\end{array}$ \\
\hline Glycerol monostearate & $40-50 \%(\min .90 \%)$ & & -- & & $<6 \% \quad(1.2 \%)$ \\
\hline$\omega$-3-Acid triglycerides & \multicolumn{2}{|c|}{$\sum$ mono- + di- $<50 \%$} & -- & $<3 \%$ & -- \\
\hline
\end{tabular}

* Purity of fatty acids: Type $\quad$ I $\quad 40-60 \%$ of stearic acid

III $\quad 90-99 \%$ of stearic acid

( ) NF 19 limits

Phosphatidylinositol (PI) is uninegatively charged and has a relatively large hydrophilic head group. It forms salts with divalent ions. In liposomes phosphatidylinositol creates a negative charge and also hydrophilizes the surface of the membrane. Phosphatidylinositol has a special significance in biological membranes; by way of enzymatic splitting it gives rise to substances that carry biochemical messages through the cell membranes into the interior of the cells.
Phosphatidic acids (PA) are dinegatively charged, since the phosphoric acid is only singly esterified with the glycerol skeleton. Incorporated in biological membranes, liposomes and micelles phosphatidic acids stabilize these particles as the electric charge present prevents them from fusing with each other. Since the head group requires very little space, the fatty acids are highly restricted in their movements. Phosphatidic acids therefore cause limited deformability in liposomes. In water,phosphatidic acids combine with divalent ions to form salts that may precipitate. 


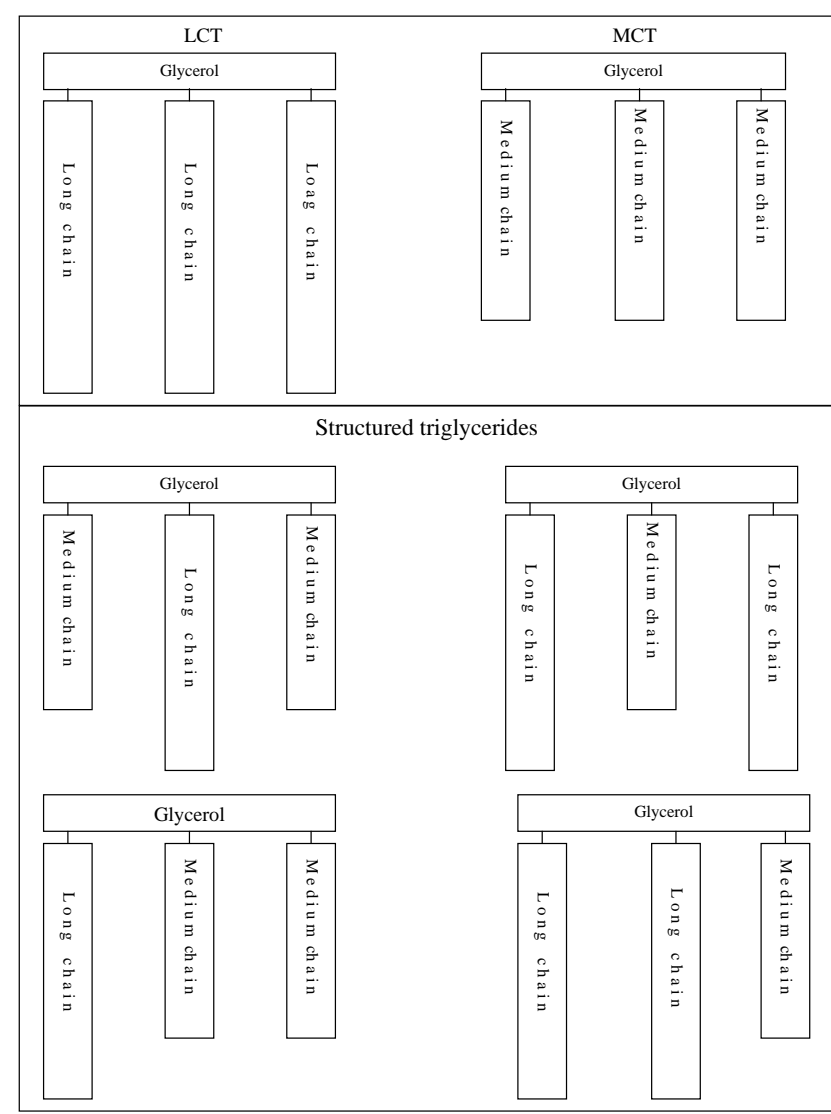

Fig. 1. Schematic drawing of structured triglycerides

A. Production using the hot homogenisation

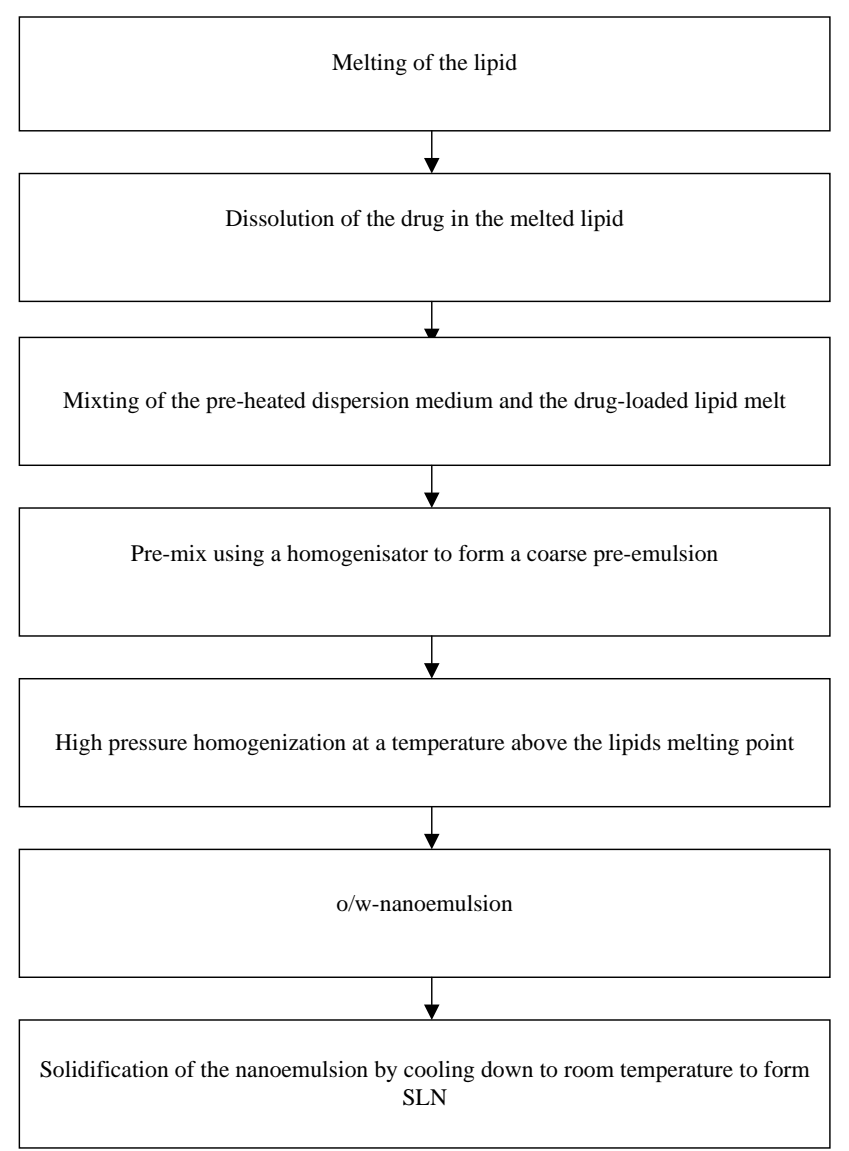

Fig. 2. Solid lipid nanoparticles for controlled drug delivery
B. Production using the cold homogenisation

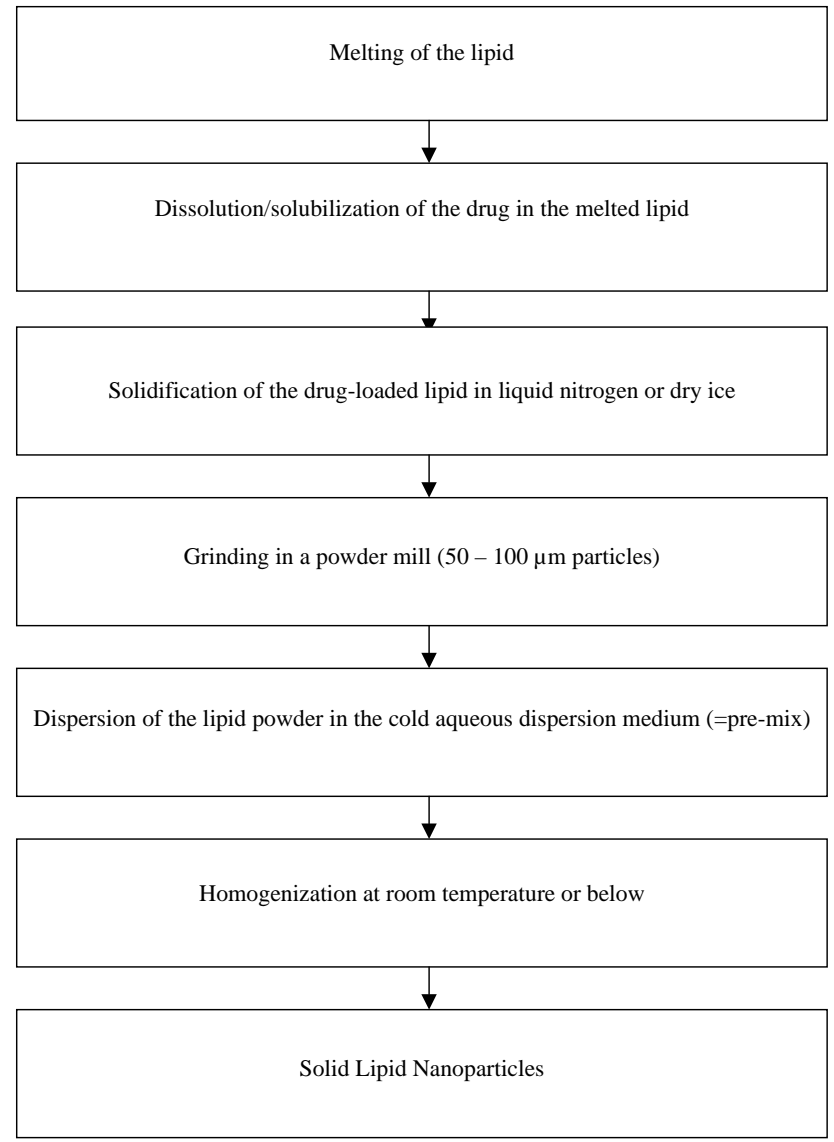

Fig. 3. Solid lipid nanoparticles for controlled drug delivery

\section{SUMMARY}

The rapid design of well-absorbed formulations for poorly water-soluble drugs continues to be problematical. The lack of regulatory acceptance of some lipid based carriers has limited their adoption for commercially available product. This paper has described formulation routes in which pharmacopoeial lipids are used as carriers of a lipophilic drugs.

Unfortunately, the wording, the style and the limits of individual monographs on homolipids in European Pharmacopoeia, United States Pharmacopoeia and Japanese Pharmacopoeia are not yet harmonised and vary from one pharmacopoeia to another.

Widening range of acceptable carriers based on heterolipids and modified lipopoproteins is also subject of this mini-review.There is a large number of potentially useful new phospholipids whose properties are claimed, especially in the patent literature, which still await for industrial application in pharmaceutical dosage forms. All sites of phospholipids can be selectively modified by enzymatic catalysis.By coupling the phospholipase action with well-established chemical transformations, natural and unnatural phospholipids can be 
prepared.They offer a useful formulation route for drugs that, until now have been difficult to to administer oraly.

For better understanding how to design and evaluate lipid-based peroral formulations may serve recently published reviews ${ }^{30,31}$.

\section{REFERENCES}

1. Charman, W. N., Porter, C. J. H., Mithani, S., Dressman, J. B. (1997) Physicochemical and physiological mechanisms for the effects food on drug absorption: The effect of lipids and $\mathrm{pH}$. J. Pharm. Sci., 86, 269-282 .

2. Fleischer, D., Li, C., Zhou, Y., Pao, L-H., Karim, A. (1999) Drug, meal and formulations influencing drug absorption after oral administration. Clin. Pharmacokinet., 36, 233-254.

3. Constantinides, P. P. (1995) Lipid microemulsions for improving drug dissolution and oral absorption: Physical and biopharmaceutical aspects. Pharm. Res., 11, 1561-1572.

4. Lawrence, M. J. (1996) Microemulsion as drug delivery vehicles. Curr. Opin. Colloid. Interface Sci., 1, 826-832.

5. Humberstone, A. J., Charman, W. N. (1997) Lipid-based vehicles for the oral delivery of poorly water-soluble drugs. Adv. Drud. Del. Rev., 25, 103-128.

6. Serajuddin, A. T. M. (1999) Solid dispersion of poorly watersoluble drugs: Early promises, subsequent problems and recent breakthroughs. J. Pharm. Sci., 88, 1058-1066.

7. Amidon, G. L., Lennernas, H., Shah, V. P., Crison, J. R. (1995) A theoretical basis for a biopharmaceutical drug classification: The correlation of in-vitro drug product dissolution and in-vivo bioavailability. Pharm. Res., 12, 413-419.

8. Brunner, L. J., Bai, S. (2000) Effect of dietary oil intake on hepatic cytochrome P 450 activity in the rat. J. Pharm. Sci., 89, 1022-1027.

9. Tsevegsuren, N., Aitzetmuller, K., Bruhl, L., Werner, G. (2000) Seed oil fatty acids of mongolian Compositae: The trans- fatty acids of Heteropappus hispidus, Asterothamnus centrali-asiaticus and Artemisia palustris. J. High Resol. Chromatogr., 23, 360-366.

10. Bell, S. J., Bradley, D., Forse, R. A., Bistrian, B. R. (1997) The new dietary fats in health and disease. J. Am. Diet. Assoc. 97, 280-286.

11. Lee, K. T., Akoh, C. C. (1996) Immobilized lipase-catalyzed production of structured Lipids with eicosapentaenoic acid at specific positions. J. Am. Oil Chem. Soc., 73, 611-615.

12. Huang, K. S., Akoh, C. C. (1996) Enzymatic synthesis of structured lipids - Transesterification of of triolein and capryliuc acidethylester. J. Am. Oil Chem. Soc., 73,245-250 .
13. Másson, M., Loftsson, T., Haraldsson, G. G. (2000) Marine lipids for prodrugs, soft compounds and other pharmaceutical applications. Pharmazie, 55, 172-177.

14. Hallgren, B. (1983) in: Ether Lipids. Biochemical and biomedical aspects, (Mangold H. K.,Paltauf F., eds.), Academic Press, New York, pp. 261-275.

15. Pérez-Camino, M. C., Moreda, W., Cert, A. (1996) Determination of diacylglycerol isomers in vegetable oils by solid-phase extraction followed by gas chromatography on a polar phase. J. Chromatogr., A721, 305-314.

16. Schneider, M. (1997) Industrial production of phospholipids-lecithin processing. Lipid Technology, September 109-116.Technology, September 109-116.

17. Anonym (1994) Sojae Lecithinum. Pharmaeuropa, 6, 279.

18. Verleysen, K., Sandra, P. (1997) Analysis of phospholipids in lecithins. Separation According to hydrophobicity by lowering the temperature. J. High Resol. Chromatogr. 20, 337-339.

19. Bijsterbosch, M. K., Van Berkel, T. J. C. (1990) Uptake of lactosylated low-density lipoprotein by galactose-specific receptors in rat liver. Biochemical Journal (London), 270, 233-239.

20. Pitas, R. E., Boyles, J., Mahley, R.V., Bissel, D. M. (1985) Uptake of chemically modified low density lipoproteins in vivo is mediated by specific endothelial cells. J. Cell Biol., 100, 103-117.

21. Ashwell, G., Morell, A. G. (1974) The role of surface carbohydrates in the hepatic recognition and transport of circulating glycoproteins. Adv. Enzymol., 41, 99-128.

22. Peyrot, M., Sautereau, A. M., Rabanel, T. M., Nguyen, F., Tocanne, J. F., Samain, D. (1994) Int. J. Pharm., 102, 25.

23. Bach, A. C., Babayan, V. K. (1982) Medium chain triglycerides. Amer. J. Clin. Nutrit., 36, 950-962 .

24. Borgström, B. (1988) in: Boekus Gastroenterology, 4th ed. (Berk J. E., Saunders W. B., eds.), Saunders W. B., Philadelphia, pp. 1510-1519.

25. Yhi-Fu, S. (1987) in: Physiology of the Gastrointestinal Tract, 2 nd ed. (Johnson L. R., ed.), Raven Press, New York, pp. 1527-1556.

26. Behrens, D., Fricker, R., Bodoky, A., Drewe, J., Harder, F., Heberer, M. (1996) Comparison of cyclosporin A absorption from LCT and MCT solutions following intrajejunal administration in conscious dogs. J. Pharm. Sci., 85, 666-668.

27. Larsson, K. (1994) Lipids - Molecular organisation, Physical functions and Technical applications. The Oily Press Ltd., Dundee, p. 2.

28. Vyas, S. P., Jaitely, V., Kanaujia, P. (1997) Self-assembling supramolecular biovectors: a new dimension in novel drug delivery systems. Pharmazie, 52, 259-267.

29. Velíšek, J. (1999) Fats and other lipids in Chemie potravin 1, Ossis, Tábor, p. 91.

30. Charman, W. N. (2000) Lipids, lipophilic drugs and oral delivery Some emerging Concepts. J. Pharm. Sci., 89, 967-978.

31. Bowtle, W. (2000) Lipid formulations for oral drug delivery. Pharmaceutical Technology Europe, 12 (9), 20-30. 